\title{
Study of Relationship between Personality Traits and Emotion Expression of Emergency Nurses in Tehran Hospitals
}

\author{
Roghayeh Eaghbaliziarat ${ }^{1, *,(D)}$, Masoumeh Najafi ${ }^{2}$ Tahereh Sarboozi \\ Hosseinabadi ${ }^{3}$,
}

${ }^{1}$ MSc, Department of Internal-Surgical Nursing, Faculty of Nursing and Midwifery, Tehran University of Medical Sciences, Tehran, Iran

${ }^{2}$ MSc, Department of Nursing, Asadabad Faculty of Medical Sciences, Asadabad, Iran

${ }^{3} \mathrm{MSc}$, Department of Nursing, School of Nursing and Midwifery, Torbat Heydariyeh University of Medical Sciences, Torbat Heydariyeh, Iran

* Corresponding author: Roghaieh Eaghbal Ziarat, MSc, Department of Internal-Surgical Nursing, Faculty of Nursing and Midwifery, Tehran University of Medical Sciences, Tehran, Iran. E-mail: sahar_eghbali@yahoo.com

Received: 30 Jan 2018

Accepted: 06 Sep 2018

\begin{abstract}
Introduction: The purpose of present study was the study of relationship between personality traits and its dimensions with emotion expression (impulse intensity, expressiveness) of emergency nurses in Tehran hospitals.
\end{abstract}

Methods: This research is descriptive and correlational. The statistical population of the study consisted of all nurses of the emergency nurses of Tehran hospitals in 2017. The sample consisted of 300 nurses who were randomly selected.

Results: The results of this study showed that there is a significant relationship between the components of personality traits (psychoanalytic, extraversion, accountability, agreeableness and passion for new experiences) and emotional expression (impulse intensity and expressiveness). Also, the findings of the canonical loading test showed that the agreeableness is most effective in the expression component, and the extraversion has the most effect on intensity of impulse than the other components.

Conclusions: Personality Dimensions, emotion expression and descending / increasing of job process trend of nurses operate in a continuous and consistent manner that predicts the job future.

Keywords: Personality Traits, Emotion, Nurses, Emergency

(c) 2018 Iranian Nursing Scientific Association (INA) 


\title{
ارتباط ويرگىهاى شخصيتى و شيوههاى ابراز هيجان برستاران بخش اورزانس بيمارستانهاى شهر تهران
}

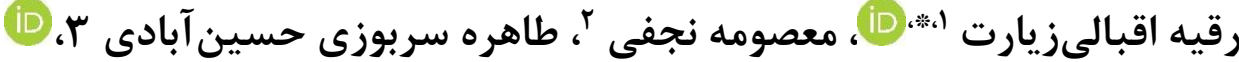

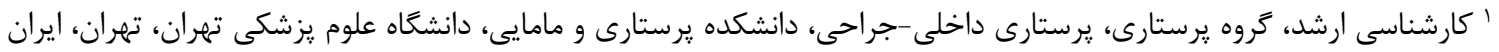

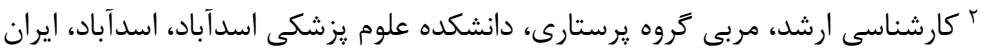

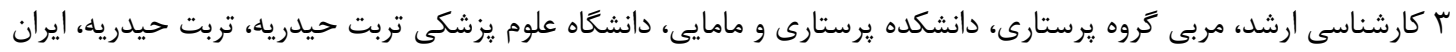

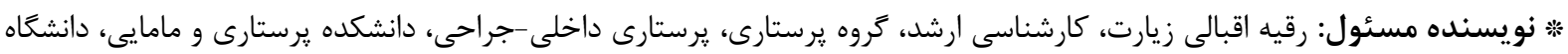

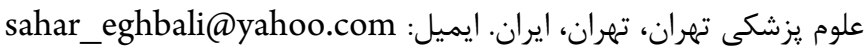

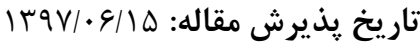

تاريخ دريافت مقاله: • || || || || ||

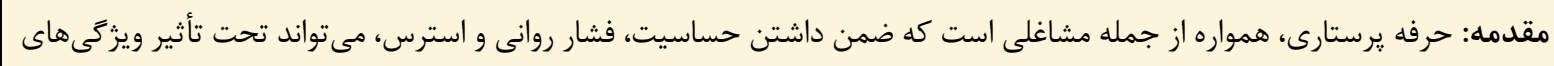

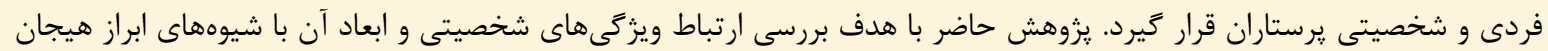

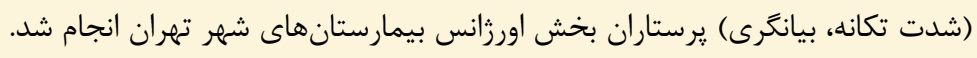

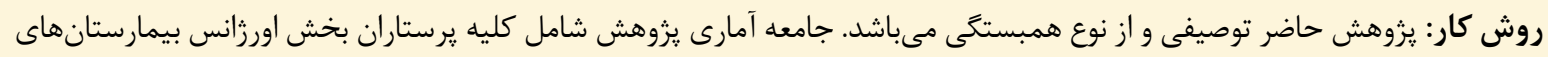

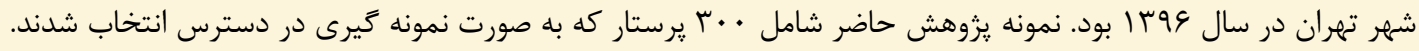

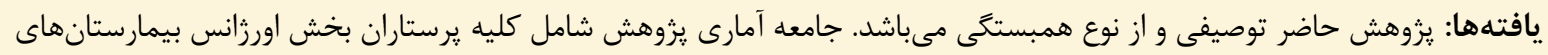

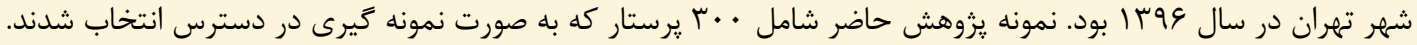

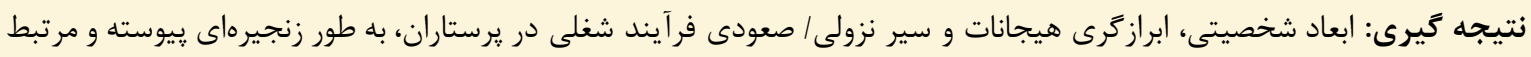

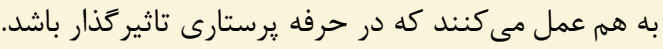

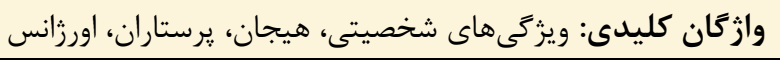

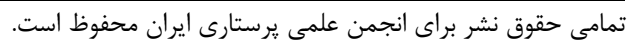

جمله ترس، احساس كناه، اضطراب و نفرت و دستياجگى است.

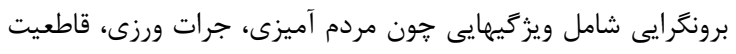

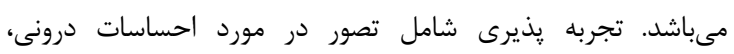

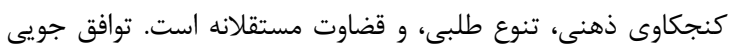

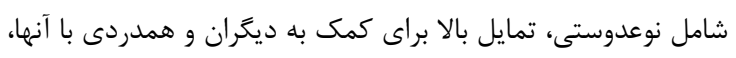

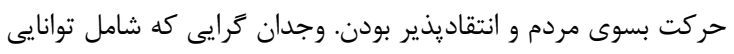

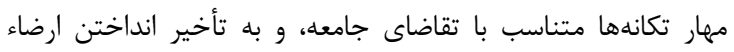

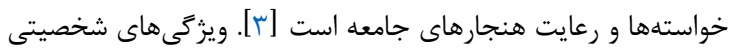

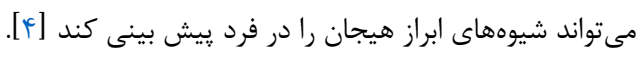

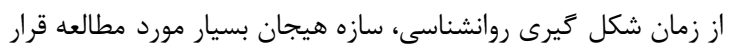

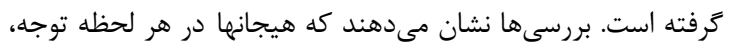

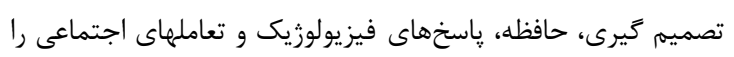

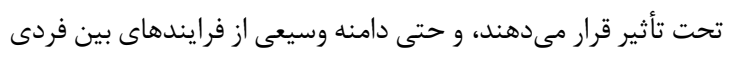

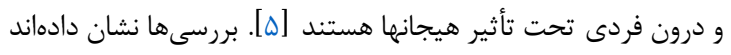

مقدمه

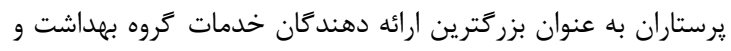

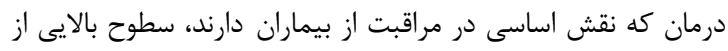

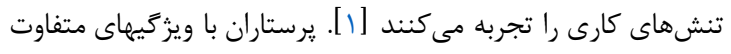

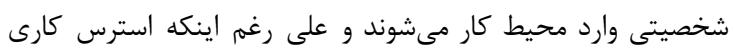

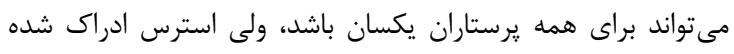

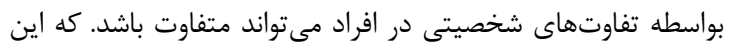

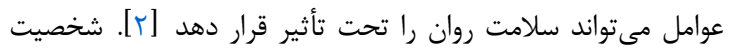

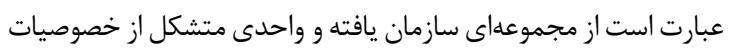

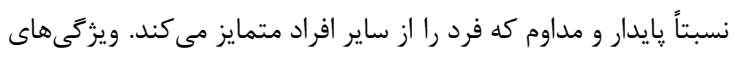

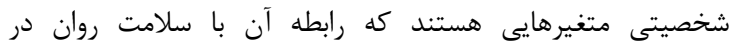

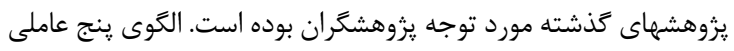

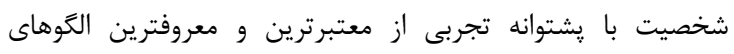

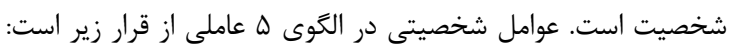

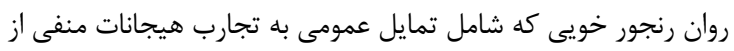




\section{روش كار}

يروهش حاضر توصيفى و از نوع همبستكى مىباشد. جامعه آمارى

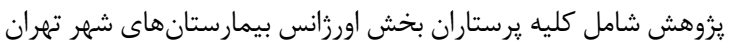

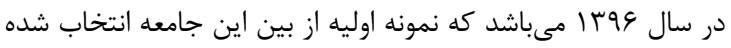

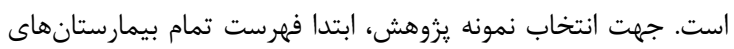

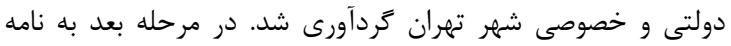

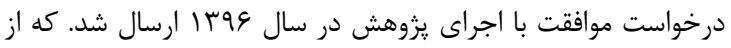

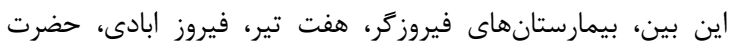

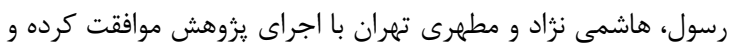

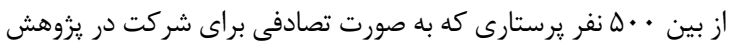

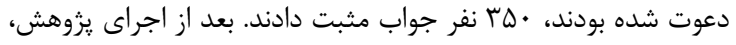

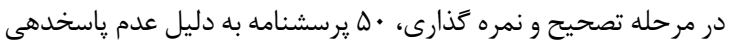

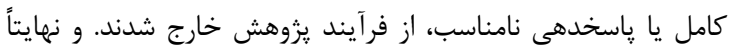

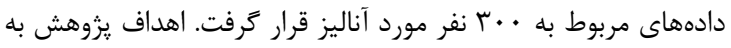

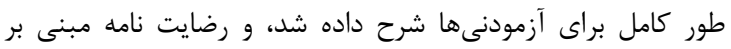

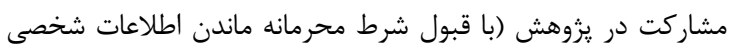
آزمودنى ها)، اخذ شد.

يرسشنامه شخصيتى ينج عامل نئو: كاســتا و مك كــــ درى در ســال

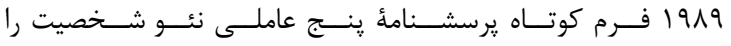

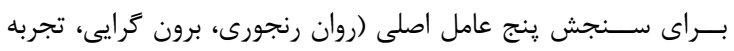

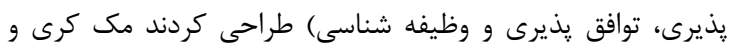

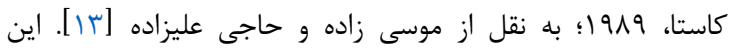

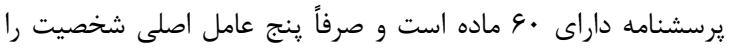

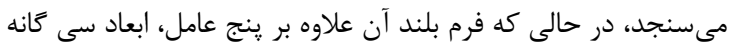

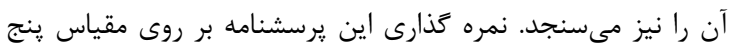

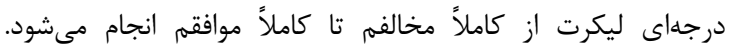

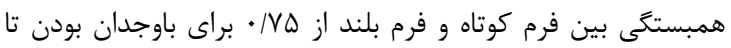

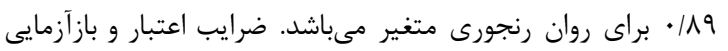

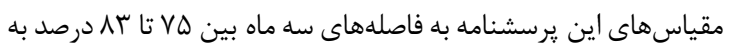

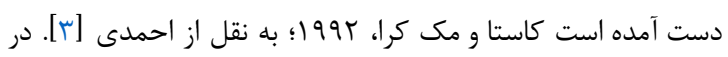

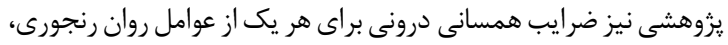

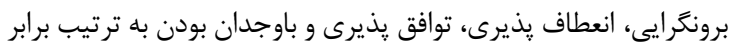

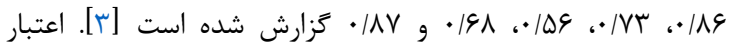

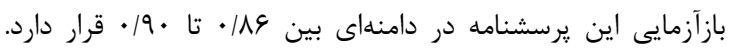

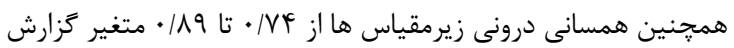

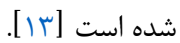

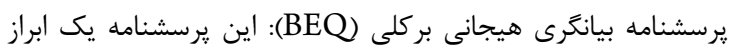

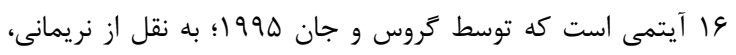

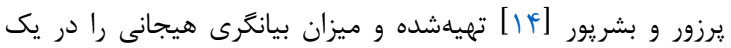

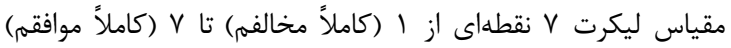

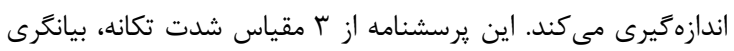

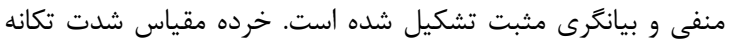

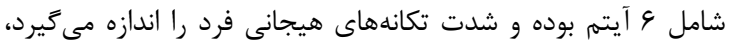

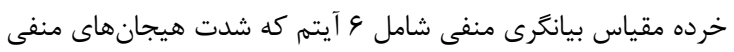

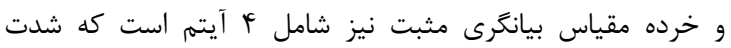

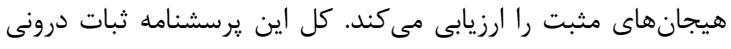

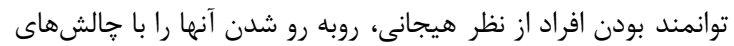

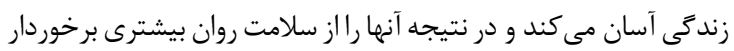

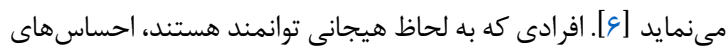

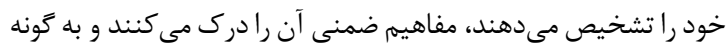

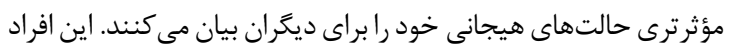

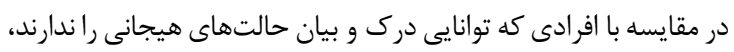

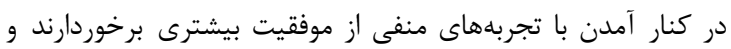

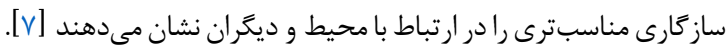

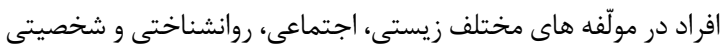

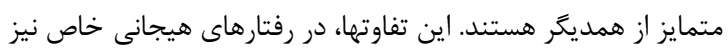

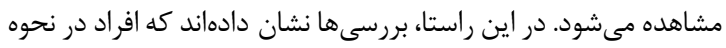

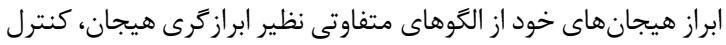

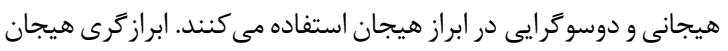

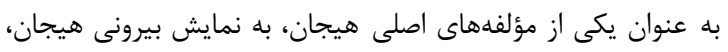

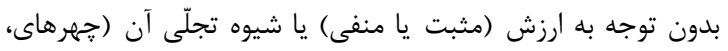

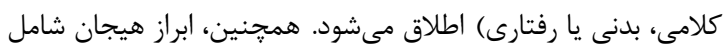

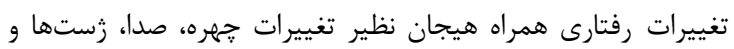

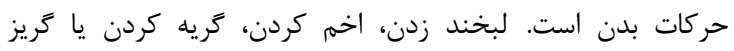

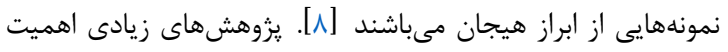

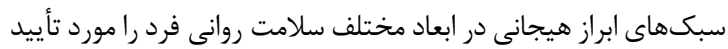

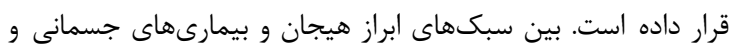

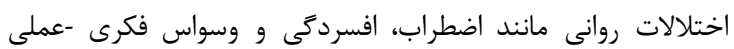

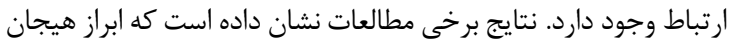

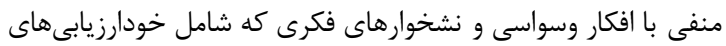

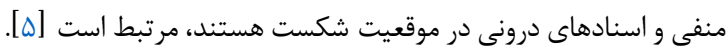

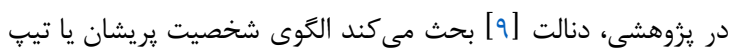

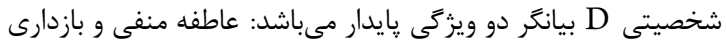

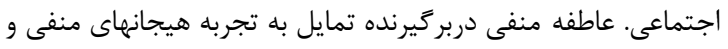

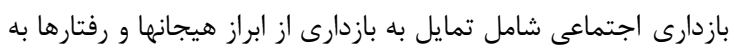

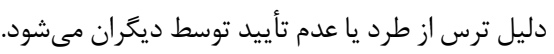

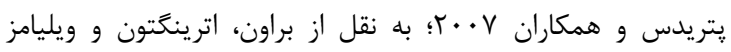
(Brown, Etherington \& Williams)

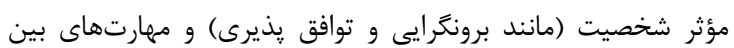

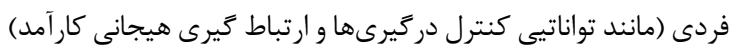

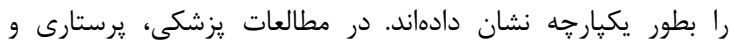

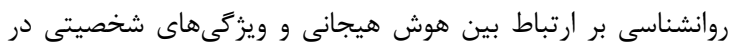

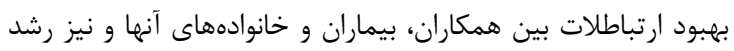

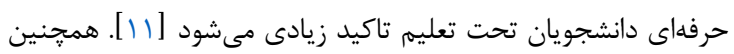

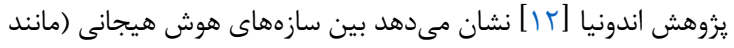

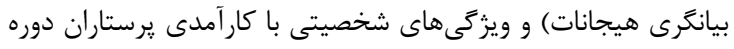

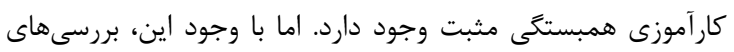

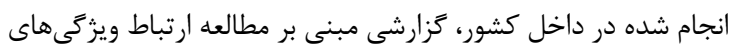

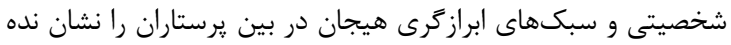

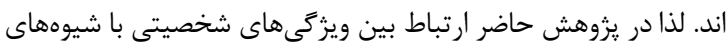

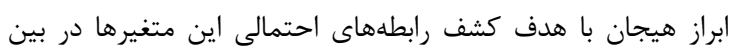
يرستاران بخش اورزانس مورد بررسى قرار مى هي عيرد. 
يافتهها

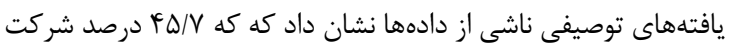

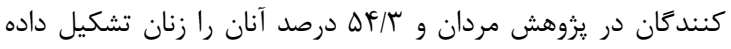

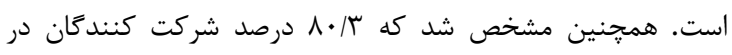

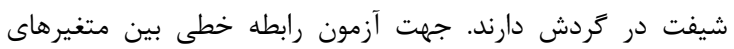

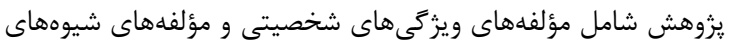

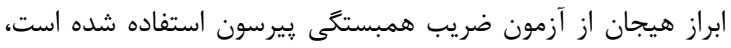

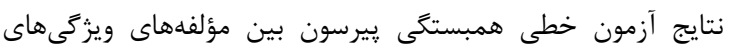

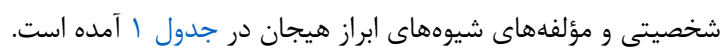

بالايى نشان داده و پايايى بازآزمايى خوبى دارد. اعتبار همخرا و واگراى

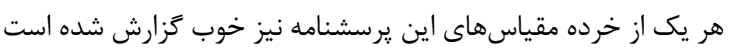

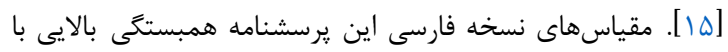

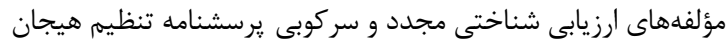

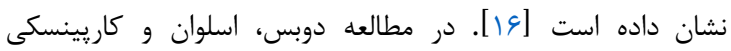

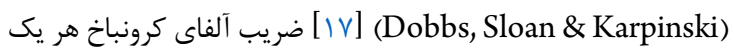

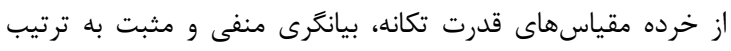

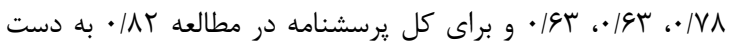

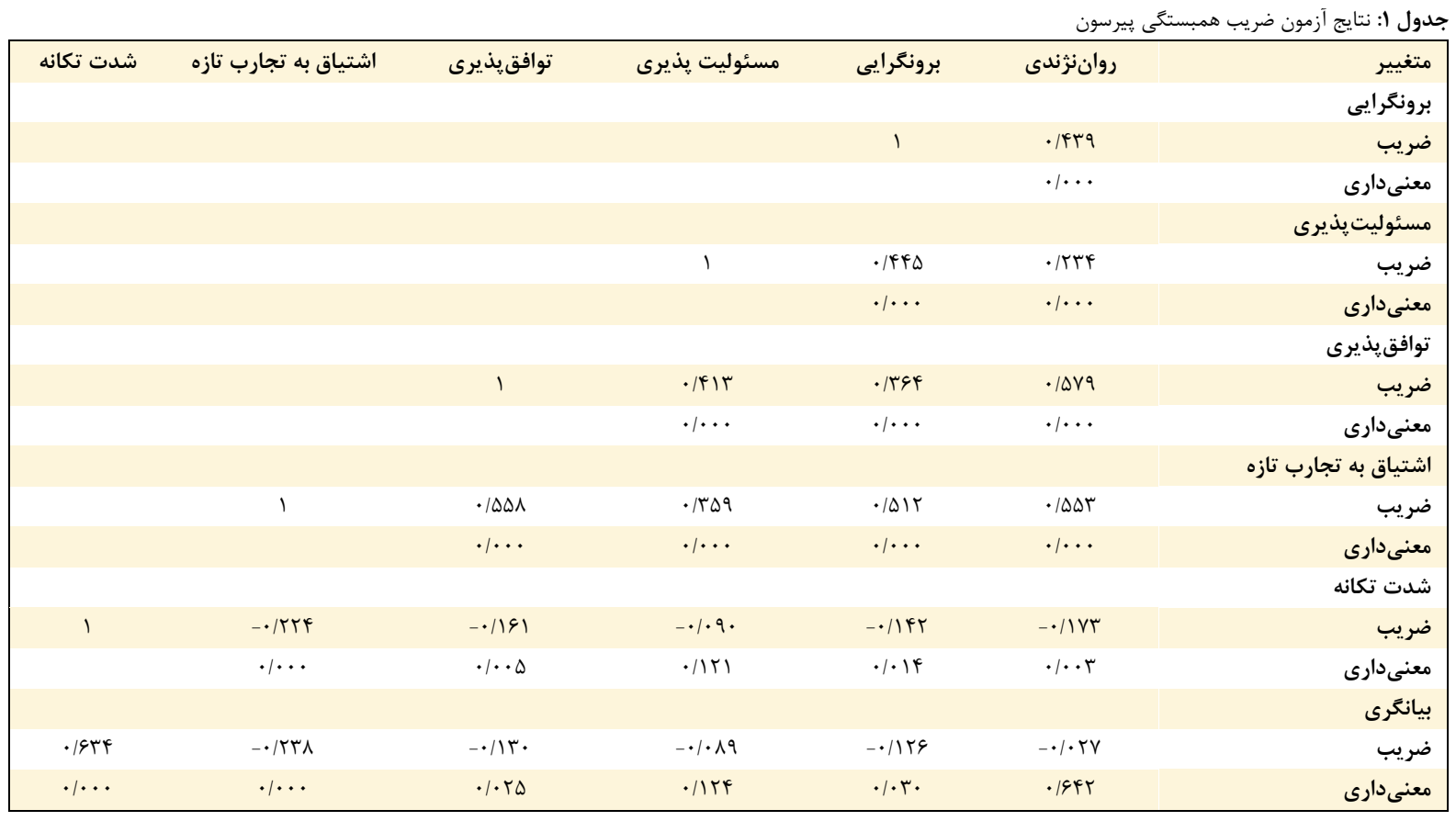

مسئوليتيذيرى كه در سطح اطمينان ه9 درصد رابطه خطى ندان

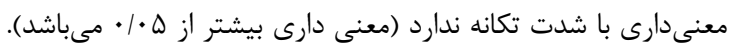

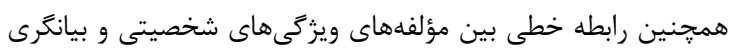

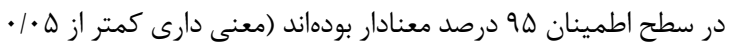

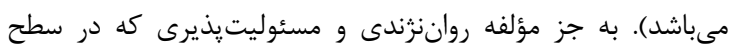

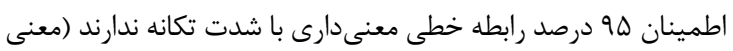
دارى بيشتر از ه • • • مىباشد).
با توجه به سطح معنادارى به دست آمده، رابطه خطى بين مؤلفههاى

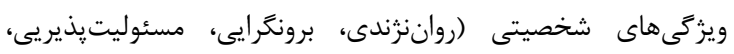
توافقيذيرى و اشتياق به تجارب تازه) در سطح اطمينان 99 درصد

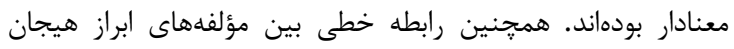

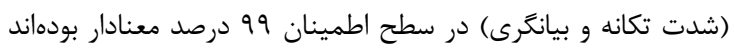

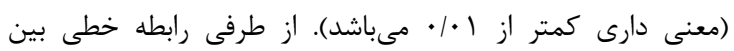

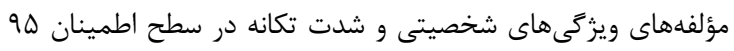

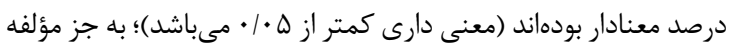

جدول ז: آزمون كاى اسكور بار تلت (Bartlett's Chi-Squared Test) بين مؤلفههاى ويرگى هاى شخصيتى و شيوههاى ابراز هيجان

\begin{tabular}{|c|c|c|c|c|c|c|}
\hline لانداى ويلكز & سطح معنى دارى & درجه آزادى & كاىاسكر & ضريب تبيين كانونى & ضريب كانونى & تابع كانونى \\
\hline$\cdot / 4 V D$ & $\cdot / \cdots$ & 1. & $r / 9 / I V \Delta$ & $\cdot 10 \cdot 9$ & $\cdot / V 11$ & 1 \\
\hline . &.$/ \cdot T \Delta$ & f & $11 / \cdot \Delta r$ &.$/ \cdot r V$ & .1195 & $r$ \\
\hline
\end{tabular}

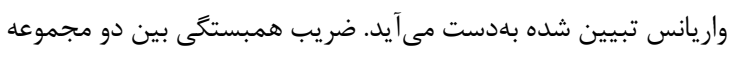

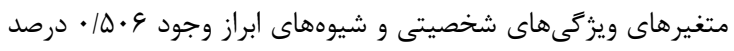

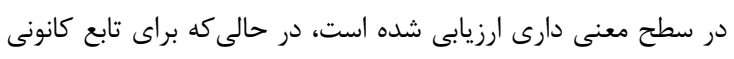
دوم روابط ضعيفتر ارزيابى شده است.
هر دو همبستخى كانونى از نظر آمارى معنى دار بوده و بيانكً وجود دو

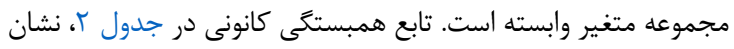

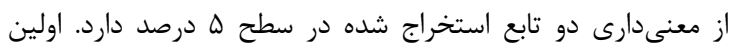

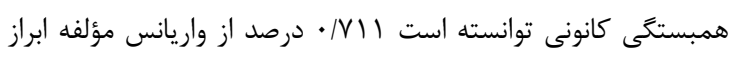
هيجان را تبيين كند كه با مجذور كردن مقدار همبستكى كانونى، مقدار 
جدول ب: جدول ضرايب كانونى استاندارد براى متغير كانونى

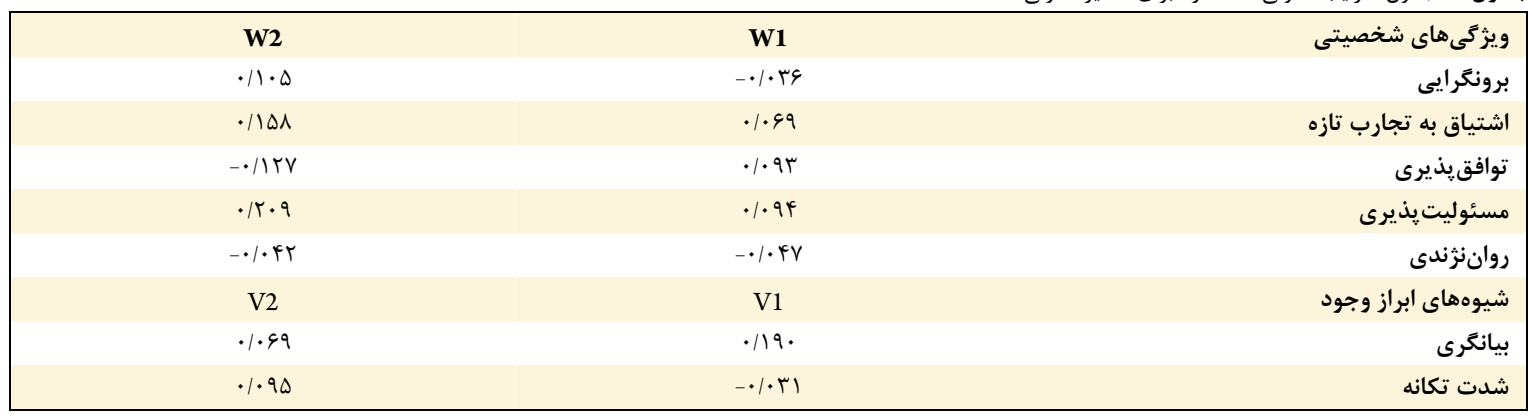

شدت تكانه يايين مىباشد. اين امر نشان مى دهد كه بهبود ويزگى هاى شخصيتى مىتواند موجب بهبود شيوههاى ابراز وجود شود. در تابع دوم

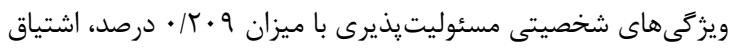

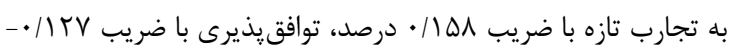

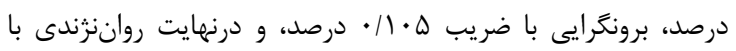
ضريب FT F • •- درصد نقش داشتهاند. و در شيوههاى ابراز وجود در

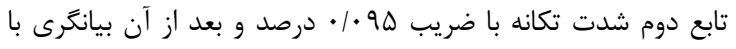
ضريب 99.

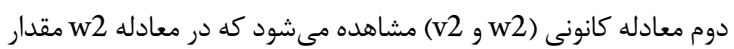

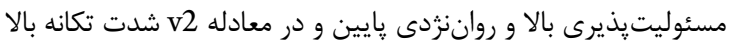

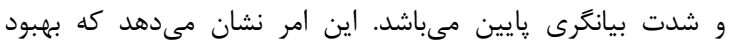
ويزگَىهاى شخصيتى مى تواند موجب بهبود شيوههاى ابراز وجود شود.
براساس ضرايب كانونى استاندارد شده (وزنهاى كانونى) براى اولين

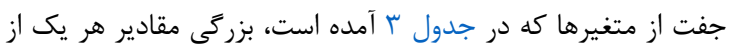

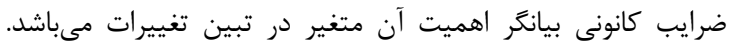

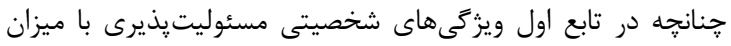

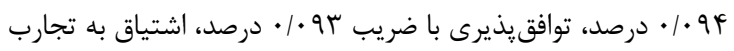

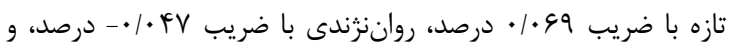

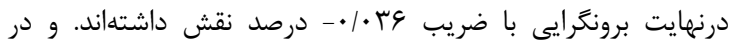

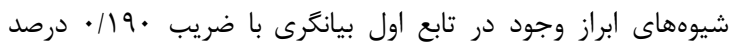

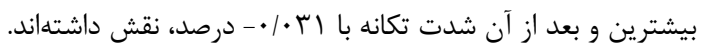

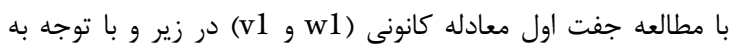
همبستخى بالاى آنها مشاهده مىشود كه در معادله W1 مقدار مسئوليتيذيرى بالا و برونگرايى يايين و در معادله v1 بيانگرى بالا و

جدول f: بار كانونى متغير اصلى با متغير خود

\begin{tabular}{|c|c|c|}
\hline W2 & W1 & ويزگكى هاى شخصيتى \\
\hline$\cdot / 4 \vee \wedge$ & - - NAt & برونكَرايى \\
\hline$\cdot / 194$ & . Isस & اشتياق به تجارب تازه \\
\hline-.1194 & . Mrs & توافقيذيرى \\
\hline$\cdot /$ / & - IATT & مسئوليت يذيرى \\
\hline.$- / . t r$ & $\cdot / r 4 q$ & روانزندى \\
\hline $\mathrm{V} 2$ & V1 & شيوههاى ابراز وجود \\
\hline$\cdot /$ IV &.$/ 94 \wedge$ & بيانكرى \\
\hline.$/ 949$ & - •/TFt & شدت تكانه \\
\hline
\end{tabular}

مسئوليتيذيرى، توافقيذيرى، اشتياق به تجارب تازه و روانترندى سهمه

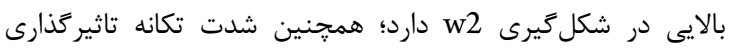

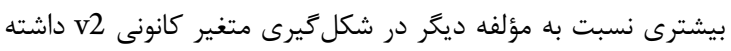
است.
مطابق با جدول f توافقيذيرى نسبت به مسئوليتيذيرى، برونكرايى،

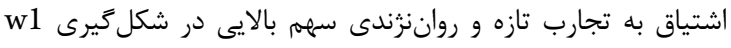

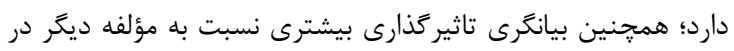

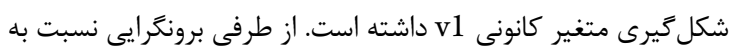




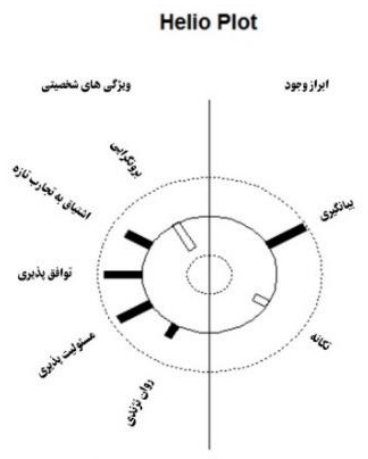

تصوير ا: نمودار هيلو براى تابع كانونى اول

جدول ه: بار كانونى متقابل متغير اصلى با متغير كانونى متضاد خود

\begin{tabular}{|c|c|c|}
\hline W2 & W1 & ويرَّى هاى شخصيتى \\
\hline . TTA & $\cdot|\Delta \Delta|$ & برونغرايى \\
\hline$\cdot 1 \cdot r V$ & $\cdot / 4 \cdot \Delta$ & اشتياق به تجارب تازه \\
\hline$\cdot 1 \cdot 49$ & .1999 & توافقيذيرى \\
\hline$\cdot / 1 \Delta F$ & $.19 \mathrm{VV}$ & مسئوليت يذيرى \\
\hline$\cdot / \cdots$ &.$/ 14 I$ & روان \\
\hline V2 & V1 & شيوههاى ابراز وجود \\
\hline$\cdot 11 \cdots$ & $\cdot / 1999$ & بيانكرى \\
\hline - MAT &.$/ 11 \mathrm{~V}$ & شدت تكانه \\
\hline
\end{tabular}

تكانه سهرم بيشترى در توزيعهاى متغيرهاى كانونى w2 و v2 داشتهاند. يافتهها نشان مى دهد برونگرايى نسبت به بقيه مولفهها در مؤلفه شدت دئن تكانه بيشترين تأثير را دارد.
مطابق با بارهاى كانونى متقابل مندرج در جدول ه مؤلفه توافقيذيرى

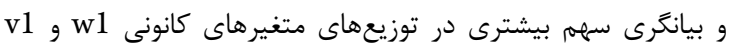
داشتهاند. يافتهها نشان مىدهد توافقيذيرى نسبت به بقيه مولفهها در

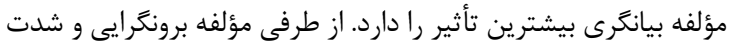

Helio Plot

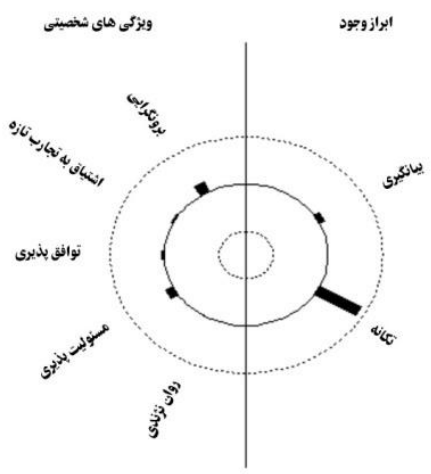

تصوير r: نمودار هيلو براى تابع كانونى دوم

\begin{tabular}{|c|c|c|c|}
\hline كل & تابع كانونى دوم & 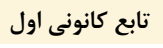 & 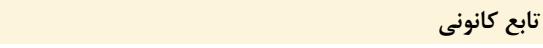 \\
\hline$\cdot / R \Delta I$ &. & $\cdot / T F A$ & مؤلفه ويثرَى هاى شخصيتى بلوسيله شيوههاى ابراز وجود \\
\hline$\cdot / T V D$ & $\cdot 1 \cdot 11$ & $\cdot / r \Delta V$ & مؤلفه شيوههاى ابراز وجود بهوسيله ويثزى هاى شخصيتى \\
\hline
\end{tabular}

دماستفاده شده است كه در آن، درجه هميوشانى بين (Coefficients

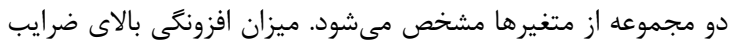

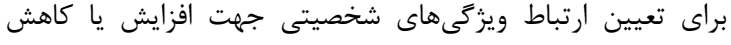

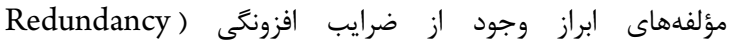


نتيجه آن، تمايل فرد به كسب تجارب جديد و قرار كرفتن در

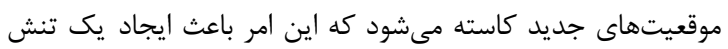

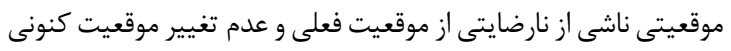

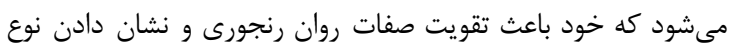

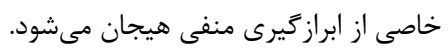

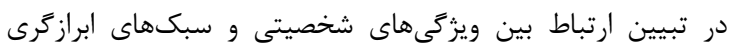

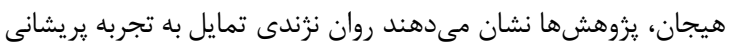

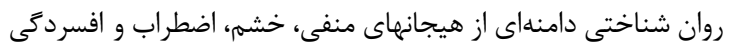

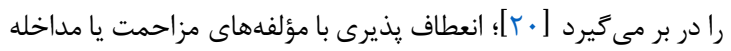

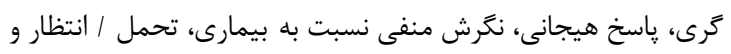

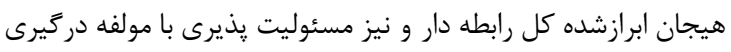

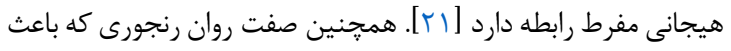
به وجود آمدن مشكلات عاطفى و هيجانى زيادى نظير افسردكى و وارد إنى

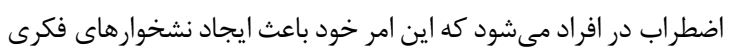

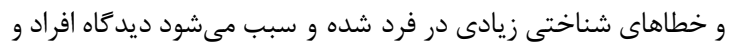

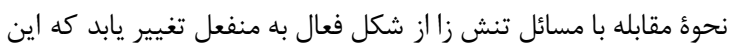

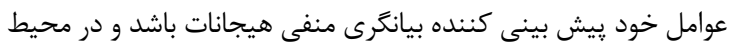

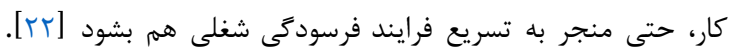

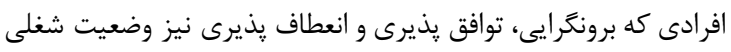

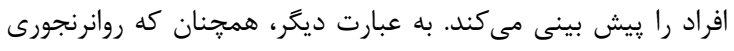

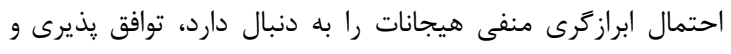

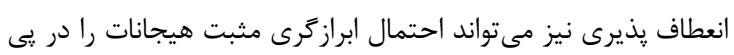

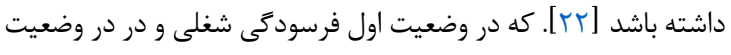
دوم يِيشرفت و رضايت شغلى قابل يِيش بينى است. هيجانها

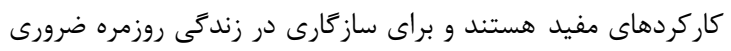

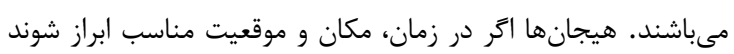

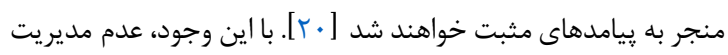

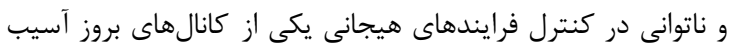
شناسى روانى و بيمارىهاى روان تنى است.

\section{نتيجه تيرى}

ابعاد شخصيتى، ابرازَّى هيجانات و سير نزولى/ سعودى فرآيند شغلى ئى

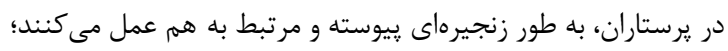

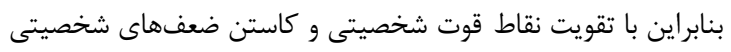

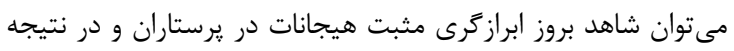
افزايش سلامت روان و رضايت شغلى در آنها بورد مثرد

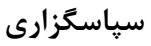

بدين وسيله از رؤساى محترم بيمارستانهايى كه اجازه دسترسى به

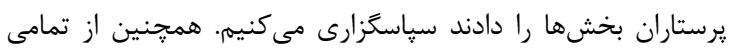

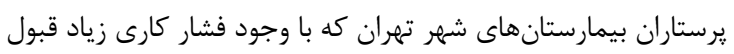

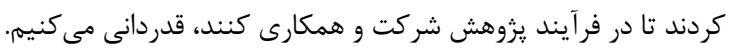

تضاد منافع

نويسندًان مقاله اعلام مى مارند كه در نغارش اين مقاله هيج كَونه تضاد

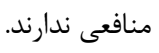

\section{References}

1. Garrosa E, Moreno-Jimenez B, Liang Y, Gonzalez JL. The relationship between socio-demographic variables, job
كانونى نشان از توانايى بالاى آنها در يِيشبينى متغيرهاى وابسته دارد. ضريب شاخص افزونكى همانند R در ركرسيون است كه براساس نتايج

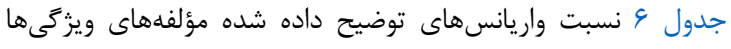

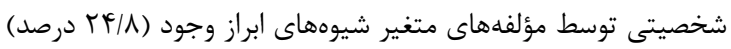

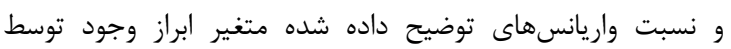

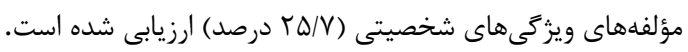

\section{بحث}

يزوهش حاضر به بررسى ارتباط بين ويزگكىهاى شخصيتى و ابرازكرى

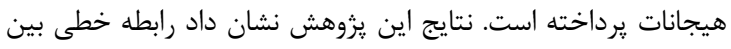

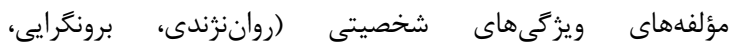

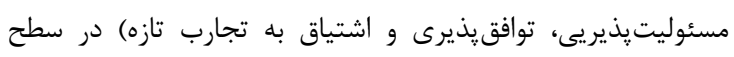

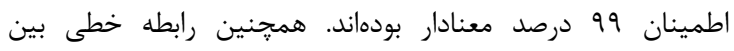

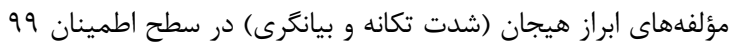

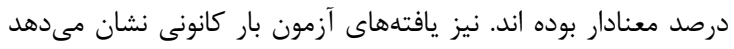

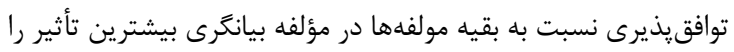

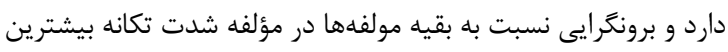

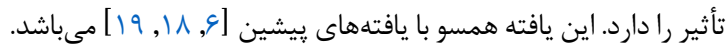

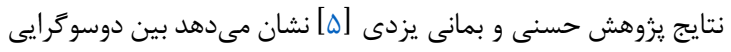

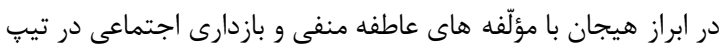

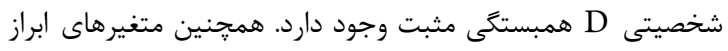

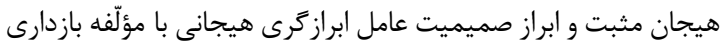

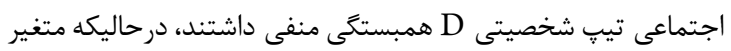

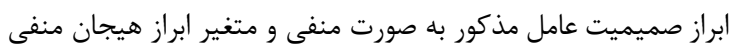

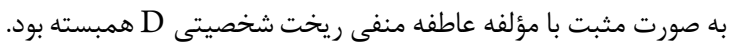

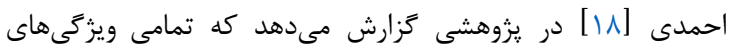

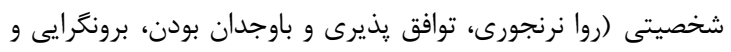

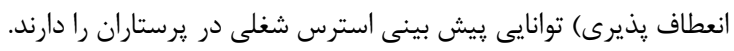

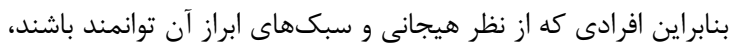

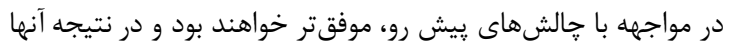

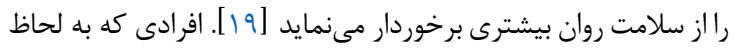

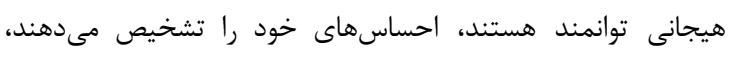

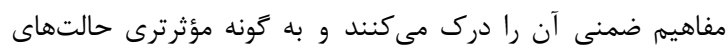

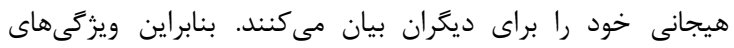

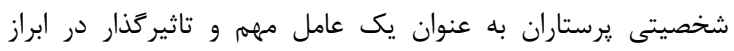
هيجانات آنها مىباشد. از طرف ديكر، افرادى كه از صفات روان رنجورى بالاترى نسبت به ديكر

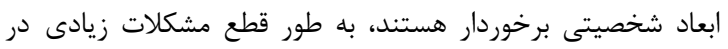

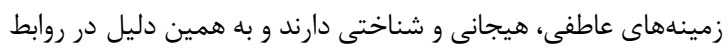

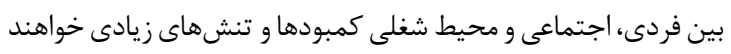

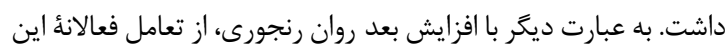

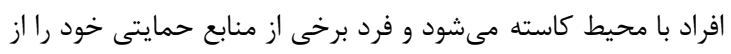

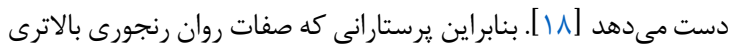

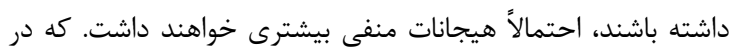


stressors, burnout, and hardy personality in nurses: an exploratory study. Int J Nurs Stud. 2008;45(3):418-27. doi: 10.1016/j.ijnurstu.2006.09.003 pmid: 17109862

2. Bagherinia H, Yamini M, Ildarabadi E, Bagherinia F. Relationship between personality traits and mental health with resilience mediation in nurses. J Sabzevar Univ Med Sci. 2016;22(6): 1063-70.

3. Ahmadi MS. The Relationship Between the five-factor Personality Traits and the Emotional Intelligence of Male and Female Miane Islamic Azad University Students. Knowledge Res Appl Psychol. 2012;13(2):44-53.

4. Denollet J, Martens EJ, Nyklicek I, Conraads VM, de Gelder B. Clinical events in coronary patients who report low distress: adverse effect of repressive coping. Health Psychol. 2008;27(3):302-8. doi: 10.1037/02786133.27.3.302 pmid: 18624593

5. Hasani J, Bemani Yazdi B. The relationship between emotional expression styles and Type $\mathrm{D}$ personality. Med Sci J Islamic Azad Univ Tehran 2015;25(2):141-50.

6. King CR, Hinds PS. Quality of life from nursing and patient perspectives: theory, research, practice. UK Jones \& Bartlett Publishers; 2003.

7. Goleman D. Emotional intelligence. New York: Bantam books; 1995.

8. Shahgholian M, Moradi A, Kafee M. Relationship of alexithymia with emotional expression styles and general health among university students. Iran J Psychiatry Clin Psychol. 2007;13(3):238-48.

9. Denollet J. Type D personality. A potential risk factor refined. J Psychosom Res. 2000;49(4):255-66. pmid: 11119782

10. Brown T, Etherington J, Williams B. Emotional intelligence and personality traits as predictors of undergraduate occupational therapy students' teamwork skills: A cross-sectional study. $\mathrm{Br} \mathrm{J}$ Occup Ther. 2017;80(7):432-9. doi: 10.1002/oti.1443

11. Beauvais AM, Brady N, O'Shea ER, Griffin MT. Emotional intelligence and nursing performance among nursing students. Nurse Educ Today. 2011;31(4):396401. doi: 10.1016/j.nedt.2010.07.013 pmid: 20739106

12. Andonian L. Emotional intelligence, self-efficacy, and occupational therapy students' fieldwork performance. Occup Ther Health Care. 2013;27(3):201-15. doi: 10.3109/07380577.2012.763199 pmid: 23855607
13. Mousazadeh O, Haji Alizadeh K. Prediction of Depression Based on Dysfunctional Attitudes, Personality Traits, and Family Communication Patterns among Patients with Epilepsy. J Shefaye Khatam. 2017;5(4):44-53. doi: 10.18869/acadpub.shefa.5.4.47

14. Narimani M, Porzour P, Basharpour S. Comparison of negative mood setting and expressive expression in students with and without Special learning disorder. QJ Res Educ Syst. 2016;9(31):69-90.

15. Gross JJ, John OP. Facets of emotional expressivity: Three self-report factors and their correlates. Pers Individ Differ 1995;19(4):555-68.

16. Basharpoor S, Molavi P, Sheykhi S, Khanjani S, Rajabi M, Mosavi SA. The relationship between emotion regulation and emotion expression styles with bullying behaviors in adolescent Students. J Ardabil Univ Med Sci. 2013;13(3):264-75.

17. Dobbs JL, Sloan DM, Karpinski A. A psychometric investigation of two self-report measures of emotional expressivity. Pers Individ Differ. 2007;43(4):693-702. doi: 10.1016/j.paid.2007.01.010

18. Ahmadi M. Predicting Job Stress and Burnout based on Personality Characteristics of Nurses. Knowledge Res Appl Psychol. 2015;17(2):98-107.

19. Dobewall H, Aavik T, Konstabel K, Schwartz SH, Realo A. A comparison of self-other agreement in personal values versus the Big Five personality traits. J Res Pers 2014;50:110. doi: $10.1016 /$ j.jrp.2014.01.004

20. Rahdari M, Modarres Gharavi M, Tabibi Z. On the relationship between personality traits and level of expressed emotion in mothers of schizophrenic patients. J Fundam Ment Health. 2010;1(45):438-47.

21. Carra G, Cazzullo CL, Clerici M. The association between expressed emotion, illness severity and subjective burden of care in relatives of patients with schizophrenia. Findings from an Italian population. BMC Psychiatry. 2012;12(29):140. doi: 10.1186/1471-244X-12-140 pmid: 22974195

22. Swider BW, Zimmerman RD. Born to burnout: A metaanalytic path model of personality, job burnout, and work outcomes. J Vocat Behav. 2010;76(3):487-506. doi: 10.1016/j.jvb.2010.01.003 